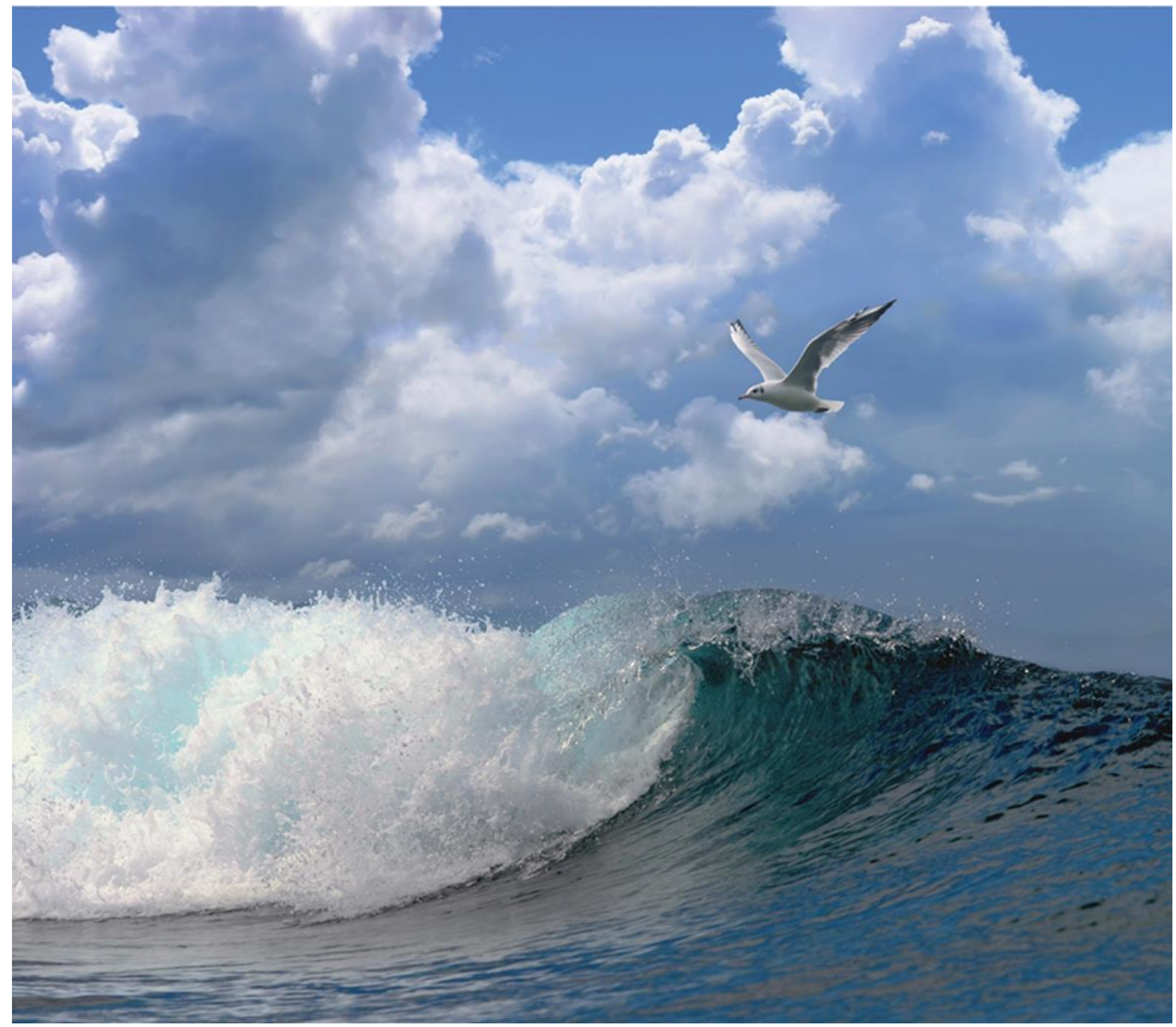

\title{
Bestandsopname van mosselen op mosselkweekpercelen in de Waddenzee in december 2018
}




\section{Bestandsopname van mosselen op mosselkweekpercelen in de Waddenzee in december 2018}

Auteur(s): Jacob J. Capelle \& Marnix R. van Stralen ${ }^{1}$

${ }^{1}$ Bureau Marinx, Scharendijke 
Keywords: mosselbestand, mosselkweek, Waddenzee

Opdrachtgever: Ministerie van LNV en PO Mosselcultuur

Dit rapport is gratis te downloaden van https://doi.org/10.18174/475677

Wageningen Marine Research verstrekt geen gedrukte exemplaren van rapporten.

Wageningen Marine Research is ISO 9001:2015 gecertificeerd.

\section{(C) Wageningen Marine Research}

Wageningen Marine Research, instituut binnen de rechtspersoon Stichting Wageningen Research, hierbij vertegenwoordigt door Dr. M.C.Th. Scholten, Algemeen directeur

KvK nr. 09098104,

WMR BTW nr. NL 8113.83.696.B16.

Code BIC/SWIFT address: RABONL2U

IBAN code: NL 73 RABO 0373599285
Wageningen Marine Research aanvaardt geen aansprakelijkheid voor gevolgschade, noch voor schade welke voortvloeit uit toepassingen van de resultaten van werkzaamheden of andere gegevens verkregen van Wageningen Marine Research opdrachtgever vrijwaart Wageningen Marine Research van aanspraken van derden in verband met deze toepassing. Alle rechten voorbehouden. Niets uit deze uitgave mag weergegeven en/of gepubliceerd worden, gefotokopieerd of op enige andere manier gebruikt worden zonder schriftelijke toestemming van de uitgever of auteur. 


\section{Inhoud}

$\begin{array}{lr}\text { Samenvatting } & 4\end{array}$

$1 \quad$ Inleiding $r$

2 Werkwijze $\quad 6$

2.1 Methode $\quad 6$

$\begin{array}{lll}2.2 & \text { Berekeningen } & 7\end{array}$

$\begin{array}{llr}3 & \text { Resultaten } & 8\end{array}$

$4 \quad$ Discussie en conclusie $r$

$\begin{array}{llr}5 & \text { Literatuur } & 13\end{array}$

$\begin{array}{lr}\text { Verantwoording } & 14\end{array}$

$\begin{array}{llr}\text { Bijlage } 1 \quad \text { Monstergrid } & 15\end{array}$

$\begin{array}{lr}\text { Bijlage } 2 \text { Evaluatie aanpassing monstergrid } & 18\end{array}$

$\begin{array}{lr}\text { Bijlage } 3 \text { Protocol monstername } & \mathbf{2 1}\end{array}$

$\begin{array}{lr}\text { Bijlage } 4 \text { Kaarten mosseldichtheid per grootteklasse. } & 23\end{array}$ 


\section{Samenvatting}

Een van de uitgangspunten bij de mosselzaadvisserij is dat de omvang van het mosselbestand in de Waddenzee en daarmee het voedselaanbod voor vogels niet minder is dan in een situatie waar niet wordt gekweekt en gevist. Dat betekent dat in het najaar een zekere hoeveelheid mosselen op de kweekpercelen in de Waddenzee aanwezig dient te zijn. Voor 2018 (peildatum 1 december) is deze hoeveelheid vastgesteld op 13,8 Miljoen kg netto versgewicht. Na de voorjaarsvisserij wordt met een bestandsopname een schatting gemaakt van het bestand op de kweekpercelen (de zogenaamde 'starthoeveelheid') en wordt vervolgens bijgehouden hoeveel mosselen afgevoerd worden en hoeveel mosselen erbij komen. Een tweede bestandsopname is bedoeld om te kunnen valideren of de eerder genoemde hoeveelheid mosselen aan het begin van de winter inderdaad op de percelen aanwezig is. Voorliggende rapportage betreft de bestandsopname van mosselen op percelen in de Waddenzee in december 2018, ter validatie van de voornoemde starthoeveelheid. Hiertoe zijn in de Waddenzee alle kweekpercelen of delen van kweekpercelen waar mosselen verwacht worden in december 2018 bemonsterd. Het totale bestand op de percelen in december 2018 is hiermee geschat op 91,5 miljoen kg versgewicht. Op basis van deze schatting kan geconcludeerd worden dat de benodigde minimale hoeveelheid mosselen op 1 december 2018 ruimschoots op de percelen aanwezig was. 


\section{$1 \quad$ Inleiding}

Eén van de uitgangspunten voor de mosselzaadvisserij is dat het geheel van Vissen, Kweek en Afvoer van mosselen naar Zeeland ('VKA') niet leidt tot minder mosselen in de Waddenzee en daarmee tot minder voedsel voor overwinterende vogels dan in een situatie waarin niet zou worden gekweekt en gevist. De achtergronden hiervan zijn na te lezen in de passende beoordeling voor de mosselzaadvisserij Waddenzee (van Stralen, 2018b) en de NB-wet vergunning die voor de periode 2018-2020 door het ministerie van LNV voor deze visserij is verleend (LNV, 2018).

Dit uitgangspunt betekent dat er in het najaar een zekere minimale hoeveelheid mosselen op de percelen aanwezig moet zijn, om als voedsel voor overwinterende vogels beschikbaar te zijn. Om dat te borgen wordt na de voorjaarsvisserij met een bestandsopname een schatting gemaakt van het bestand op de kweekpercelen (de zogenaamde 'starthoeveelheid'). Vervolgens wordt bijgehouden hoeveel mosselen naar Zeeland worden afgevoerd en hoeveel mosselen erbij komen uit MZI's, visserij en andere bronnen (bijvoorbeeld 'Zuid-Noord' transporten, d.w.z. transporten van mosselen uit Zeeland naar de Waddenzee).

Als onderdeel van de vergunningverlening voor de mosselzaadvisserij in het voorjaar van 2018 is berekend dat in het najaar van 2018 (ijkmoment 1 december) een bestand van minimaal 13,8 miljoen kg netto op kweekpercelen in de Waddenzee aanwezig dient te zijn (van Stralen, 2018a).

Het mosselbestand op de percelen na de voorjaarsvisserij van 2018 is geïnventariseerd in juni 2018. Dit resulteerde in een schatting van het mosselbestand van 71 miljoen $\mathrm{kg}$ netto versgewicht. De tweede bestandsopname in december 2018, beschreven in voorliggend rapport, is bedoeld om te kunnen valideren of de eerder genoemde minimale hoeveelheid mosselen van 13,8 miljoen kg netto versgewicht aan het begin van de winter inderdaad op de percelen aanwezig was. 


\section{Werkwijze}

\section{$2.1 \quad$ Methode}

Voor de bestandsopname zijn bemonsteringsstations (hierna: stations) in een regelmatig grid over alle kweekpercelen gelegd. De bemonsteringsstations liggen in noordelijke en oostelijke richting 0,2 bij 0,2 nautische minuten uit elkaar, dit komt overeen met een gridceloppervlak van 8,26 ha. Daarbij zijn (delen van) kweekpercelen waarvan bekend is dat zij niet in het gebruik zijn, bijvoorbeeld omdat zij droogvallen of het er te hard stroomt, niet in het monsterprogramma opgenomen. In geval dat daar twijfel over was zijn deze wel in het programma opgenomen. Voor de verder achtergronden bij het opstellen van het monstergrid wordt verwezen naar Van Stralen (2013)

Om reden van efficiëntie is besloten om binnen het areaal dat wel wordt gebruikt voor mosselkweek en waar dus wordt gemonsterd onderscheid te maken tussen de meer en minder intensief benutte gedeelten. De minder frequent gebruikte percelen of gedeelte daarvan worden ook minder intensief bemonsterd door de monsterpunten daar verder uit elkaar te leggen. Sinds 2017 zijn tijdens drie opeenvolgende bestandsopnamen steeds dezelfde 526 stations bemonsterd (voorjaar van 2017 (Troost \& Van Stralen, 2017b), winter van 2017/2018 (Capelle \& van Stralen, 2018a) en voorjaar van 2018 (Capelle \& van Stralen, 2018b)). Van elk van deze 526 stations is over deze drie opnamen de kans berekend om mosselen aan te treffen als percentage: $0 \%=$ in geen van de 3 keer mosselen aangetroffen; $33 \%$ in 1 van de 3; 66\% in 2 van de 3; en $100 \%$ in 3 van de 3 bestandsopnamen. De categorieën $0 \%$ en $33 \%$ zijn vervolgens gekwalificeerd als minder intensief gebruikt en $66 \%$ en $100 \%$ als intensief gebruikt. De stations van de laatste categorie zijn in onderhavige bestandsopnamen allen bemonsterd. Van de stations in de eerste categorie is 1 op de 3 stations bemonsterd, waarbij elk station staat voor een drie keer zo groot oppervlak. Het onderzoeksprogramma kon zo worden ingekrompen van 526 naar 322 stations waarvan 215 in een fijn grid en 107 in een grof grid (Bijlage 1). De bemonstering is uitgevoerd door buitendienst medewerkers van de Waddenunit van het Ministerie van EZ vanaf de Rijksvaartuigen "Asterias" en "Phoca". Het onderzoek is begeleid en gerapporteerd door Wageningen Marine Research, met als opdrachtgever de PO Mosselcultuur en het ministerie van LNV. Per station zijn 5 happen genomen met een Van Veen bodemhapper wat resulteert in een bemonsterd oppervlak van $0.276 \mathrm{~m}^{2}$ per station. Een evaluatie naar aanleiding van de aanpassing van het monstergrid is uitgewerkt in Bijlage 2.

Monsters zijn verwerkt per station, protocol hiervoor is bijgevoegd in Bijlage 3. Per dag zijn alle vangsten voor die dag bijeengevoegd. Stations met vooral mosselzaad als vangst zijn daarbij apart gehouden van stations met voornamelijk halfwas en/of consumptie maatse mosselen. Dit levert per dag dus twee verzamelmonsters op. Aan het eind van de dag is van elk daarvan het volume bepaald (in liters) en is een deelmonster genomen van 6 liter uit het deel met voornamelijk halfwas en/of consumptie maatse mosselen en 3.5 liter uit het deel met vooral mosselzaad. Deze metingen zijn aan het eind van elk dag dat er monters verzameld zijn uitgevoerd, zodat de monsters bij het doormeten niet ouder waren dan een dag en dus nog vers waren. De handleiding voor de verwerking van deze monsters is ook bijgevoegd in Bijlage $\mathbf{3}$.

Bij de zaadvisserij maar ook bij het verzaaien van bijvoorbeeld halfwasmosselen naar Zeeland wordt gerekend in bruto hoeveelheden. Er zijn daarom ook bruto bestandsschattingen gemaakt. $\mathrm{Bij}$ de doorrekening van netto naar bruto hoeveelheden zaad en meerjarige mosselen is uitgegaan van tarrapercentages van respectievelijk $40 \%$ en $25 \%$. Dit is conform de berekeningen bij bestandsopnamen van wilde mosselbestanden (referentie?). 


\subsection{Berekeningen}

Uit de monsters die aan het einde van dag $j$ (de dagvangst) verzameld zijn (voor respectievelijk twee grootteklassen ( $i$ ): meerjarige mosselen en voor zaad) is een deelmonster genomen. De omrekenfactor van dit deelmonster naar het totale dagmonster is uitgerekend door de totale vangst per dag $(V$, liter) te delen door de hoeveelheid deelmonster ( $V d$, liter). Bij deelmonsters met veel (kleine) mosselen is soms slechts een deel van het deelmonsters doorgemeten, door het deelmonster in gelijke delen te verdelen. In dat geval is de omrekenfactor vermenigvuldigd met het aantal gelijke delen $(x)$ waarin het deelmonster is verdeeld. De omrekenfactor $(f)$ is dus als volgt opgebouwd: $f_{i, j}=$ $V_{i, j} / V d_{i, j} *_{i, j}$.

Van elk deelmonster uit zowel de dagvangst zaad als uit de dagvangst meerjarige mosselen is het gewicht aan mosselen gemeten en het aantal mosselen geteld, hierbij is onderscheid gemaakt tussen drie klassen: zaad (jaarklasse 0), halfwas (meerjarig $<30 \mathrm{~mm}$ ) en consumptiemaat (meerjarig $>45 \mathrm{~mm}$ ). Door het gewicht $(\mathrm{kg})$ aan mosselen in het deelmonster te vermenigvuldigen met de bijbehorend omrekenfactor $(f)$ is de biomassa $(\mathrm{kg})$ in het totale dagmonster uitgerekend. Daarmee is geschat wat er per dag aan biomassa zaadmosselen, halfwasmosselen en consumptiemosselen verzameld is. Deze biomassa's zijn gedeeld door het totale verzamelde volume $(V)$ van die respectievelijke dag. Het resultaat is een schatting van de biomassa aan zaadmosselen, halfwasmosselen en consumptiemosselen per liter monster $(\mathrm{kg} / \mathrm{l})$ voor elke dag dat er bemonsterd is.

Per bemonsteringsstation is de biomassa mosselen per vierkante meter $\left(B, \mathrm{~kg} / \mathrm{m}^{2}\right)$ geschat uit het verzameld volume (I) aan mosselen per bemonsteringsstation, door dit te vermenigvuldigen met respectievelijk de biomassa aan zaadmosselen, halfwasmosselen en consumptiemosselen per liter monster $(\mathrm{kg} / \mathrm{l})$ voor die dag en dit delen door het bemonsterd oppervlak $(A)$ per station (Tabel 2.1).

De netto mosselbiomassa in mosselton $(\mathrm{mt}=100 \mathrm{~kg}$ ) per gridcel $(k)$, is geschat door de biomassa per vierkante meter $\left(B, \mathrm{~kg} / \mathrm{m}^{2}\right)$ te vermenigvuldigen met de oppervlakte van de respectievelijk grove en fijne gridcel (Tabel 2.1) waarin dit monsterpunt zich bevind. De netto mosselbiomassa percelen (mt), per grootteklasse is geschat door de mosselbiomassa's van de gridcellen bij elkaar op te tellen.

Tabel 2.1 Parameters oppervlaktebepaling

\begin{tabular}{l|l|l|l}
\hline Parameter & & Eenheid & Waarde \\
\hline$A$ & bemonsterde oppervlakte per station & $\mathrm{m}^{2}$ & 0,276 \\
$g$ & Oppervlakte per gridcel, fijn grid & ha & 8,26 \\
$G$ & Oppervlakte per gridcel, grof grid & ha & 24,78 \\
\hline
\end{tabular}




\section{Resultaten}

De aangetroffen dichtheden van mosselen zijn ruimtelijk weergegeven in Figuur 3.1. Een opsplitsing voor verschillende grootteklassen is bijgevoegd in Bijlage 4. De bijbehorende bestandsgroottes zijn, samen met de resultaten uit voorgaande jaren, samengevat in Tabel 3.1 en in Figuur 3.2.

Het mosselbestand $(B)$ op de percelen in de Waddenzee begin december 2018 is geschat op 91,5 miljoen $\mathrm{kg}$ ( 915.000 mosselton, $1 \mathrm{mt}=100 \mathrm{~kg}$ ) netto versgewicht. Daarvan bestaat 52,9 miljoen kg uit mosselzaad (voornamelijk broedval 2018). Van de 38,6 miljoen kg meerjarige mosselen bestaat 11,3 miljoen kg uit halfwas mosselen (schelplengte kleiner dan $45 \mathrm{~mm}$ ) en 27,3 miljoen kg uit consumptie mosselen (schelplengte van minstens $45 \mathrm{~mm}$ ). Uitgaande van tarrapercentages van $40 \%$ en $25 \%$ voor respectievelijk mosselzaad en meerjarige mosselen komt de bruto mosselbiomassa op de percelen uit op 139,6 miljoen $\mathrm{kg}(1.396 .000 \mathrm{mt})$ versgewicht, waarvan 88,1 miljoen $\mathrm{kg}$ mosselzaad en 51,5 miljoen $\mathrm{kg}$ meerjarige mosselen.

Tabel 3.1. Het mosselbestand op mosselkweekpercelen in de Waddenzee vanaf 2004. Bij de omrekening van netto naar bruto hoeveelheden is voor mosselzaad en meerjarige mosselen uitgegaan van een tarrapercentage van resp. 40\% en $25 \%$. 1 Mosselton $(\mathrm{mt})=100 \mathrm{~kg}$. De gegevens tot en met 2011 zijn afkomstig uit (De Mesel \& Wijsman, 2011) en (Wijsman \& Jol, 2012).

\begin{tabular}{|c|c|c|c|c|c|c|c|c|}
\hline \multirow{2}{*}{$\begin{array}{l}\text { Mosselbestand } \\
\text { kweekpercelen } \\
\text { Waddenzee }\end{array}$} & \multicolumn{4}{|c|}{ Netto bestand (miljoen $\mathbf{k g}$ ) } & \multicolumn{4}{|c|}{ Bruto bestand (mt x 1000) } \\
\hline & Zaad & $\begin{array}{l}\text { Halfwas } \\
(<45 \mathrm{~mm})\end{array}$ & $\begin{array}{c}\text { Groot } \\
(\geq 45 \mathrm{~mm})\end{array}$ & Totaal & Zaad & $\begin{array}{l}\text { Halfwas } \\
(<45 \mathrm{~mm})\end{array}$ & $\begin{array}{c}\text { Groot } \\
(\geq 45 \mathrm{~mm})\end{array}$ & Totaal \\
\hline $2004-\mathrm{dec}$ & 1,0 & 15,2 & 31,9 & 48,1 & 17 & 203 & 425 & 644 \\
\hline 2005- dec & 8,9 & 0,9 & 5,2 & 14,9 & 148 & 12 & 69 & 228 \\
\hline 2006- dec & 1,0 & 5,8 & 29,0 & 35,8 & 17 & 77 & 387 & 481 \\
\hline 2007- dec & 17,5 & 2,5 & 15,3 & 35,3 & 291 & 33 & 204 & 528 \\
\hline 2008-dec & 11,8 & 2,1 & 15,8 & 29,7 & 196 & 28 & 211 & 435 \\
\hline 2009- dec & 15,4 & 2,8 & 28,3 & 46,5 & 257 & 38 & 377 & 672 \\
\hline 2010- dec & 7,6 & 11,0 & 28,9 & 47,5 & 127 & 147 & 385 & 659 \\
\hline $2011-$ dec & 8,9 & 1,3 & 11,8 & 21,9 & 148 & 17 & 157 & 322 \\
\hline $2013-$ jan & 39,6 & 1,5 & 5,6 & 46,7 & 660 & 20 & 74 & 754 \\
\hline 2013 - april & 52,5 & 1,7 & 4,7 & 58,9 & 875 & 23 & 62 & 960 \\
\hline $2013-$ dec & 14,3 & 31,1 & 4,7 & 50,1 & 238 & 415 & 63 & 716 \\
\hline 2014 - juli & 7,5 & 33,3 & 20,3 & 61,1 & 124 & 444 & 271 & 840 \\
\hline $2014-\mathrm{dec}$ & 37,7 & 7,6 & 13,4 & 58,7 & 629 & 101 & 179 & 909 \\
\hline 2015 - juni & 40,7 & 11,7 & 13,5 & 65,8 & 678 & 155 & 180 & 1013 \\
\hline $2015-\mathrm{dec}$ & 45,6 & 9,5 & 12,4 & 67,5 & 761 & 126 & 165 & 1052 \\
\hline 2016 - juni & 62,6 & 21,3 & 15,2 & 99,1 & 1044 & 284 & 202 & 1530 \\
\hline 2017 - feb & 48,1 & 14,6 & 9,1 & 71,8 & 802 & 195 & 121 & 1118 \\
\hline 2017 - juli & 80,3 & 20,4 & 18,0 & 118,8 & 1339 & 272 & 240 & 1851 \\
\hline $2018-\mathrm{feb}$ & 20,8 & 20,2 & 9,3 & 50,4 & 346 & 270 & 394 & 741 \\
\hline 2018 - juni & 25,0 & 22,3 & 23,7 & 71,0 & 416 & 297 & 316 & 1030 \\
\hline $2018-\mathrm{dec}$ & 52,9 & 11,3 & 27,3 & 91,5 & 882 & 151 & 364 & 1396 \\
\hline gem. winter '04-'18 & 22,1 & 9,2 & 16,5 & 47,8 & 368 & 123 & 220 & 711 \\
\hline
\end{tabular}




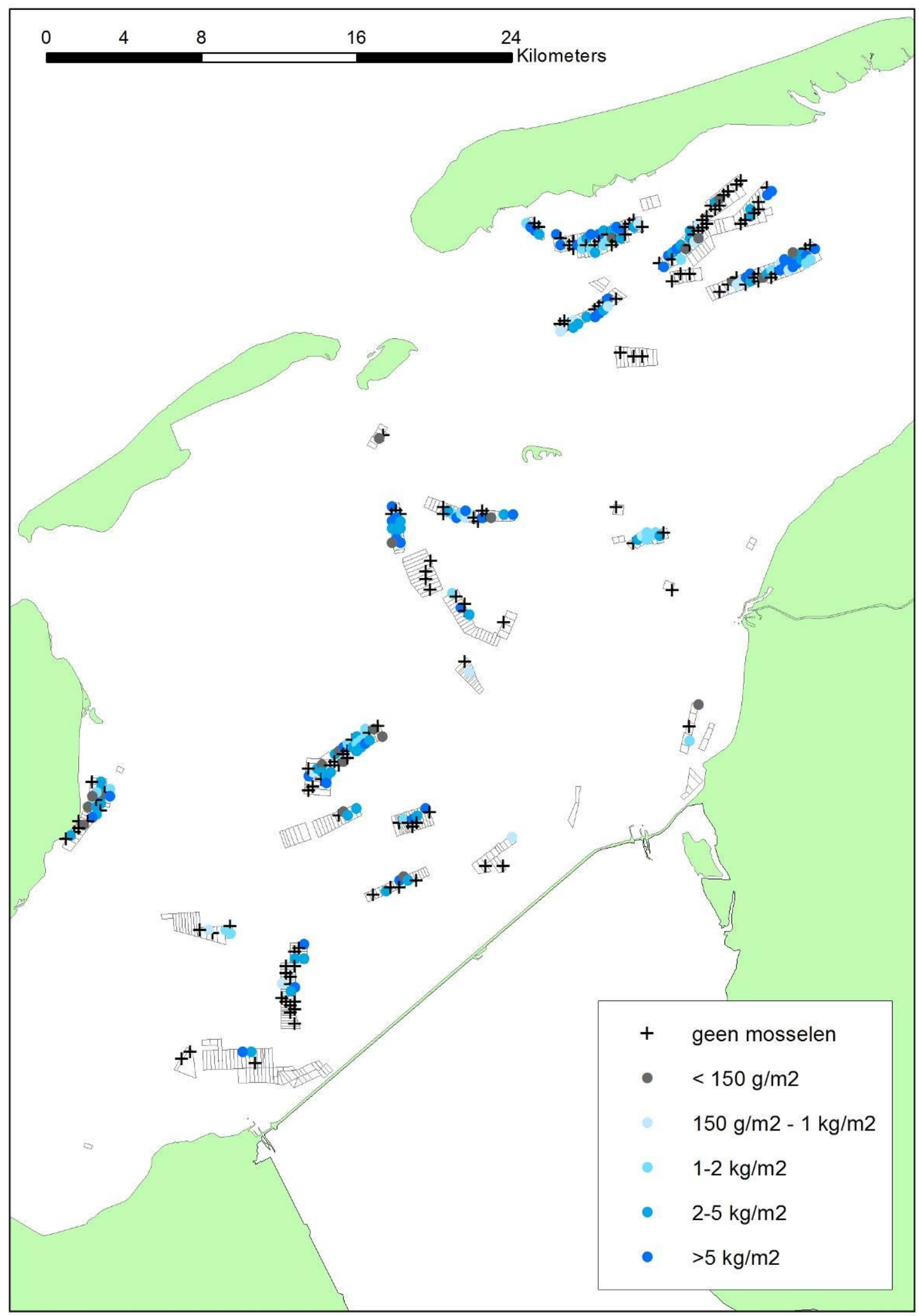

Figuur 3.1 Dichtheid van mosselen op mosselkweekpercelen in de Waddenzee in december 2018 in gram versgewicht per $m^{2}$. 


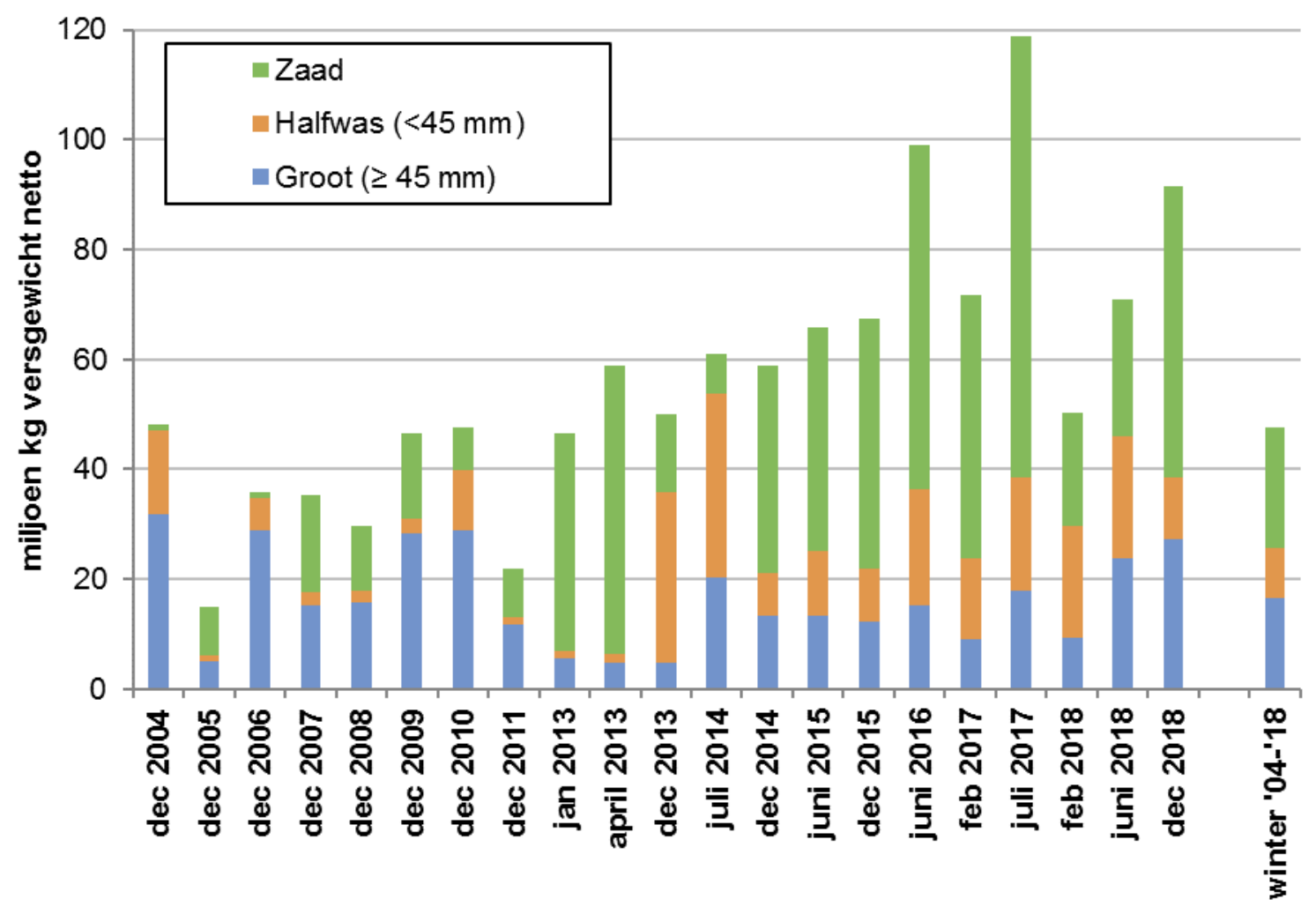

Figuur 3.2 Mosselbestand in miljoen kg netto versgewicht op mosselkweekpercelen in de Waddenzee in de periode december 2004 - december 2018 met meest rechts de gemiddelde biomassa in de winters van 2004 - 2018. De mosselen zijn onderverdeeld in mosselzaad en meerjarige mosselen groter en kleiner dan $45 \mathrm{~mm}$. De onderliggende gegevens zijn opgenomen in Tabel 3.1. 


\section{$4 \quad$ Discussie en conclusie}

Uit oogpunt van de beschikbare onderzoektijd is het programma aangepast waarbij percelen en/of perceelgedeelten waar in het verleden maar af en toe mosselen zijn aangetroffen in een lagere monsterdichtheid zijn bemonsterd dan in de voorgaande jaren. In Bijlage $\mathbf{2}$ is deze aanpassing geëvalueerd. Uit deze evaluatie komt naar voren dat er een effect is van bestandgrootte. Bij grotere mosselbestanden op de percelen wordt er intensiever gebruik gemaakt van het kweekareaal en bevindt zich een relatief groot bestand op het deel wat minder intensief gebruikt wordt. De berekeningen laten verder zien dat in de minder intensief gebruikte gebieden de gemiddelde mosseldichtheden structureel laag zijn, dit is ook evenredig met de omvang van het bestand. In de winter worden storm- en stroomgevoelige gebieden voor de mosselkweek gemeden, variatie in de winteropname is daarom minder groot zal dan in de voorjaarsopname. De bestandschattingen in de winter komen dan ook beter overeen met de bestandschattingen in het voorjaar (zowel voor de winter van ' $16 /$ '17 als ' $17 /$ '18 gemiddeld slechts $1 \%$ verschil). Het is dus vooral voor de bestandopname in de winter zinvol om dit uit te voeren volgens een gestratificeerd monstergrid. Het voornemen is dit grid ook bij de toekomstige winteropnamen te gebruiken. In het voorjaar zal volgens het oorspronkelijke (fijne) grid bemonsterd worden.

In december 2018 is met een geschat bestand van 91,5 miljoen kg versgewicht het hoogste winterbestand mosselen op de percelen gevonden sinds de metingen in 2004. Dit wordt vooral veroorzaakt door een relatief hoog bestand aan mosselzaad. De biomassa aan mosselzaad op de percelen is afkomstig van mosselen uit de najaarszaadvisserij; in het najaar van 2018 is 11,2 miljoen kg mosselzaad is opgevist, uit de MZI oogst; in 2018 is van MZIs in de Waddenzee 18,5 Mkg mosselzaad geoogst (Capelle en Van Stralen, in prep) en van het rendement van het mosselzaad op de percelen.

Als onderdeel van de vergunningverlening voor de mosselzaadvisserij in het voorjaar van 2018 is berekend dat in het najaar van 2018 een bestand van minimaal 13,8 miljoen kg netto aanwezig diende te zijn (van Stralen, 2018a). Die hoeveelheid was dus ruimschoots aanwezig op de peildatum van 1 december 2018. 


\section{$5 \quad$ Kwaliteitsborging}

Wageningen Marine Research beschikt over een ISO 9001:2015 gecertificeerd kwaliteitsmanagementsysteem. Dit certificaat is geldig tot 15 december 2021. De organisatie is gecertificeerd sinds 27 februari 2001. De certificering is uitgevoerd door DNV GL.

Het chemisch laboratorium te IJmuiden beschikt over een NEN-EN-ISO/IEC 17025:2005 accreditatie voor testlaboratoria met nummer L097. Deze accreditatie is geldig tot 1 april 2021 en is voor het eerst verleend op 27 maart 1997; deze accreditatie is verleend door de Raad voor Accreditatie. Het chemisch laboratorium heeft hierdoor aangetoond in staat te zijn op technisch bekwame wijze valide resultaten te leveren en te werken volgens de ISO17025 norm. De scope (L097) met de geaccrediteerde analysemethoden is te vinden op de website van de Raad voor Accreditatie (www.rva.nl).

Op grond van deze accreditatie is het kwaliteitskenmerk $\mathrm{Q}$ toegekend aan de resultaten van die componenten die op de scope staan vermeld, mits aan alle kwaliteitseisen is voldaan. Het kwaliteitskenmerk $Q$ staat vermeld in de tabellen met de onderzoeksresultaten. Indien het kwaliteitskenmerk $\mathrm{Q}$ niet staat vermeld is de reden hiervan vermeld.

De kwaliteit van de analysemethoden wordt op verschillende manieren gewaarborgd. De juistheid van de analysemethoden wordt regelmatig getoetst door deelname aan ringonderzoeken waaronder die georganiseerd door QUASIMEME. Indien geen ringonderzoek voorhanden is, wordt een tweede lijnscontrole uitgevoerd. Tevens wordt bij iedere meetserie een eerstelijnscontrole uitgevoerd. Naast de lijnscontroles wordende volgende algemene kwaliteitscontroles uitgevoerd:

- Blanco onderzoek.

- Terugvinding (recovery).

- Interne standaard voor borging opwerkmethode.

- Injectie standard.

- Gevoeligheid.

Bovenstaande controles staan beschreven in Wageningen Marine Research werkvoorschrift ISW 2.10.2.105.

Indien gewenst kunnen gegevens met betrekking tot de prestatiekenmerken van de analysemethoden bij het chemisch laboratorium worden opgevraagd.

Indien sprake is van onbeheerste kwaliteit worden passende maatregelen genomen. 


\section{$6 \quad$ Literatuur}

Capelle JJ, van Stralen MR (2018a) Bestandsopname van mosselen op mosselkweekpercelen in de Waddenzee in februari 2018. Wageningen Marine Research Wageningen UR (University \& Research centre), Yerseke.

Capelle JJ, van Stralen MR (2018b) Bestandsopname van mosselen op mosselkweekpercelen in de Waddenzee in juni 2018. Wageningen Marine Research, Yerseke.

De Mesel I, Wijsman JWM (2011) Bestandsschatting mosselen op percelen in de Oosterschelde (1992-2009) en de Waddenzee (2004-2009). Yerseke.

LNV (2018) Bijlage 1; overwegingen; meerjarige vergunning; vooren najaarsmosselzaadvisserijen 20182020. Kenmerk DGAN-NB/18. Den Haag.

Troost K, Van Stralen MR (2017a) Bestandsopname van mosselen op mosselkweekpercelen in de Waddenzee in februari 2017. Wageningen Marine Research Wageningen UR (University \& Research centre), Wageningen Marine Research.

Troost K, Van Stralen MR (2017b) Bestandsopname van mosselen op mosselkweekpercelen in de Waddenzee in juli 2017, . Wageningen Marine Research Wageningen UR (University \& Research centre), Wageningen Marine Research, rapport C070/17.

Van Stralen MR (2013) Bestandsopname van mosselen op mosselkweekpercelen in de Waddenzee in de winter van 2012-2013. Marinx.

van Stralen MR (2018a) Bijlage bij het Visplan mosselzaadvisserij voorjaar 2018; Doorrekening VKA model voorjaar 2018. Marinx, Scharendijke.

van Stralen MR (2018b) Passende Beoordeling van de mosselvisserij in het sublitoraal van de Westelijke Waddenzee in de periode 2018-2020. Marinx, Scharendijke.

Wijsman JWM, Jol J (2012) Onderzoeksproject Duurzame Schelpdiervisserij (PRODUS). Deelproject 1A. Bepaling bestand op de mosselpercelen in de Waddenzee najaar 2011 (Mussel stock assessment on culture plots in the Waddensea in autumn 2012, report in Dutch). Wageningen IMARES, Yerseke, pp. 48. 


\section{Verantwoording}

Rapport C041/19

Projectnummer: 4313200007

Dit rapport is met grote zorgvuldigheid tot stand gekomen. De wetenschappelijke kwaliteit is intern getoetst door een collega-onderzoeker en het verantwoordelijk lid van het managementteam van Wageningen Marine Research

Akkoord:

Brenda Walles

Onderzoeker

Handtekening:

Datum:

23 april 2019

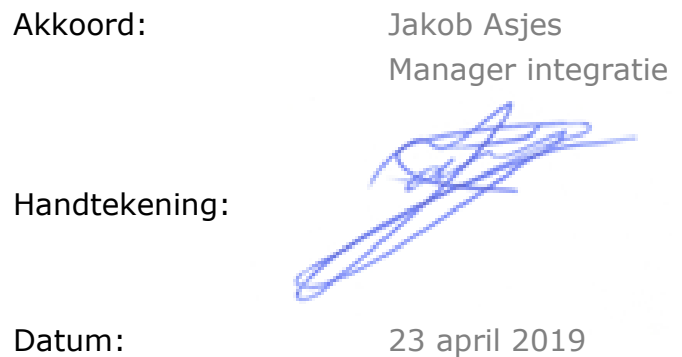




\section{Bijlage 1 Monstergrid}
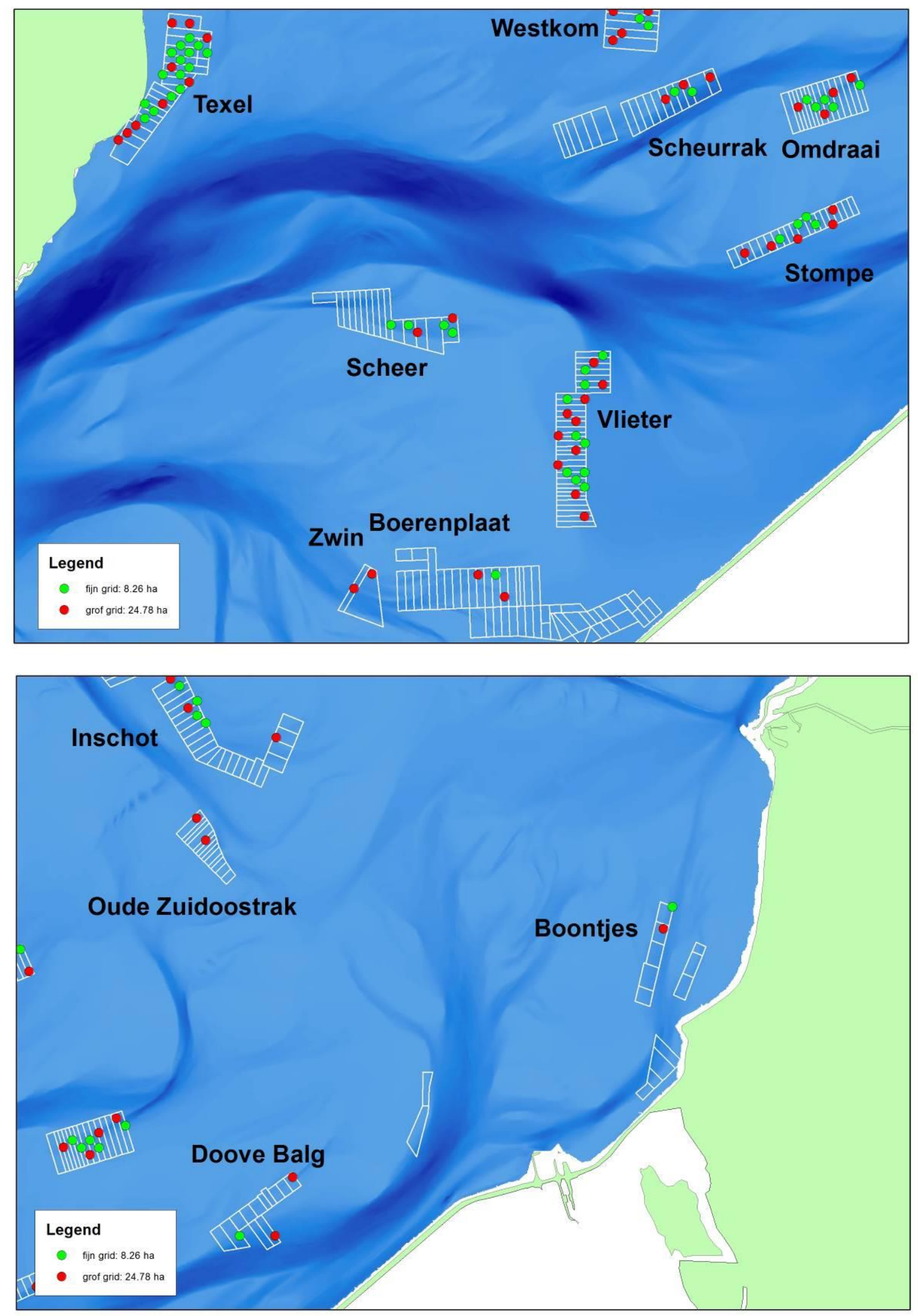

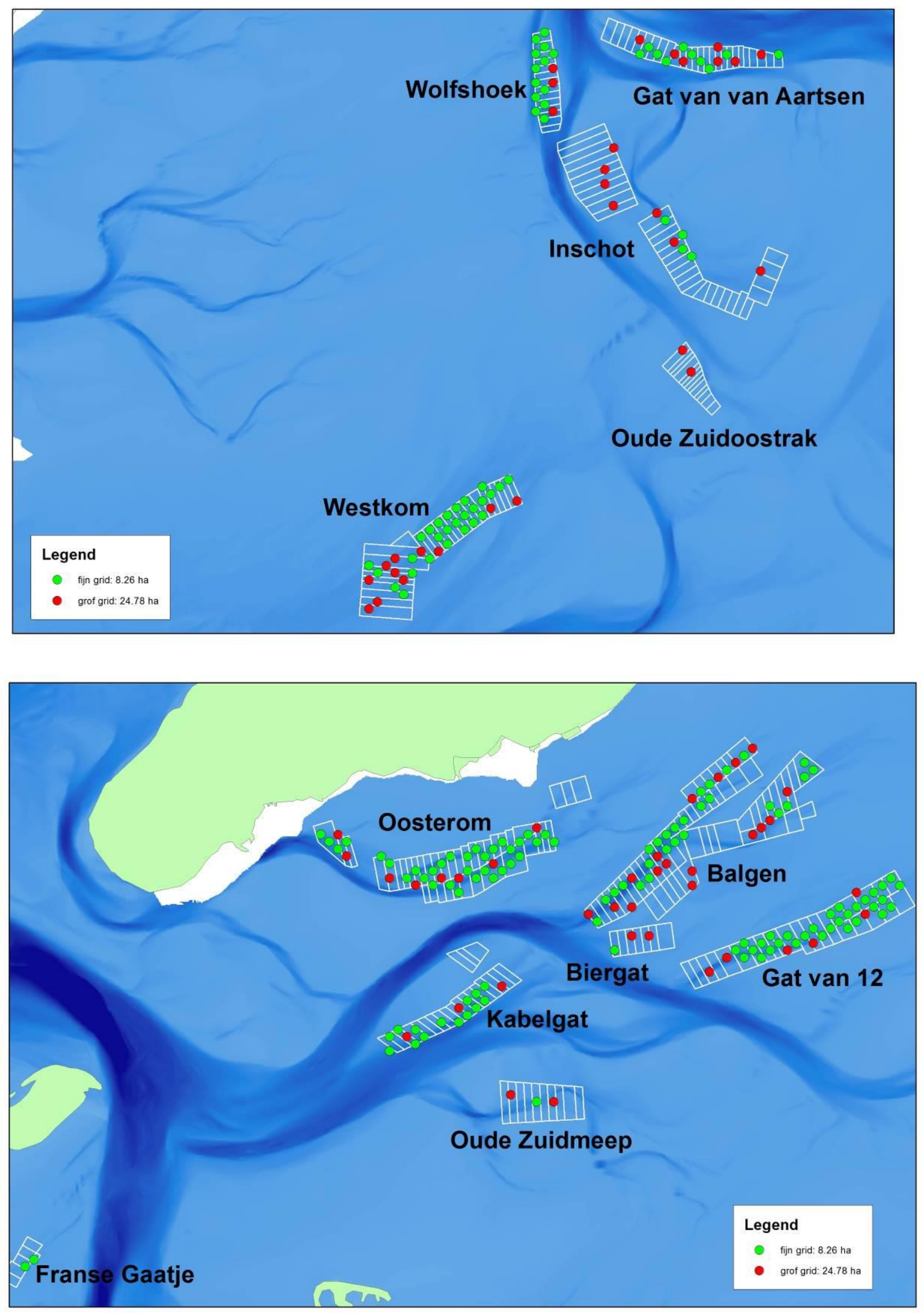


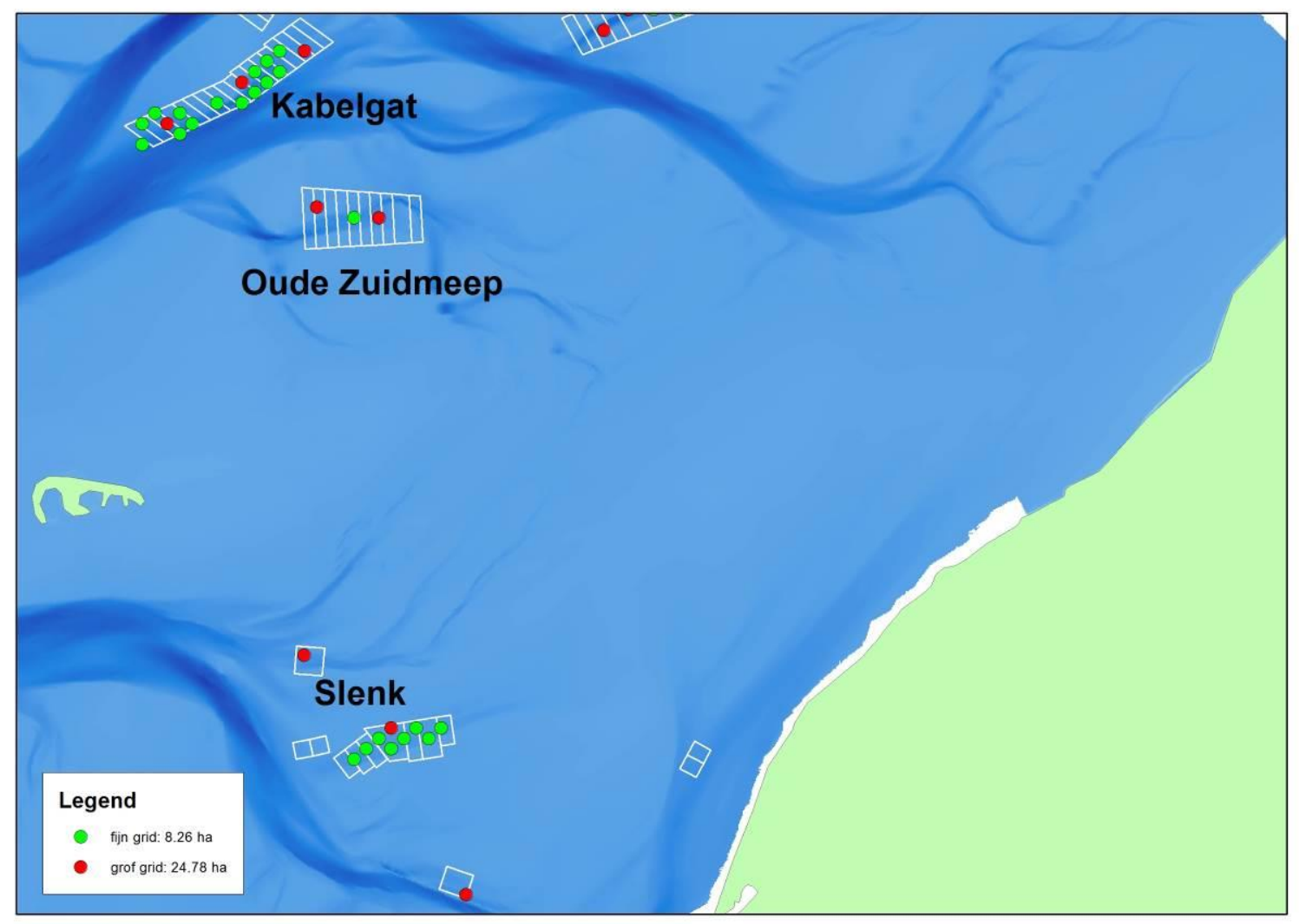




\section{Bijlage 2 Evaluatie aanpassing monstergrid}

De geschatte bestanden aan mosselen op percelen die in onderstaande analyse gebruikt worden zijn weergegeven in Figuur B2.1. Voor al deze vier opnames (m.u.v. de huidige) is het bestand herberekend met toepassing van het grove en fijne grid. In aanvulling op de bestandopnames die gebruikt zijn bij het berekenen van de trefkans van mosselen (zie: par 2.1) is ook de bestandsopname van de winter 2016/2017 gebruikt (Troost \& Van Stralen, 2017a). Voor deze opname zijn 503 stations bezocht, 23 stations minder dan voor de drie opvolgende bestandopnames. Deze opname is niet gebruikt in de berekening bij de aanpassing in het monstergrid en kan dus dienen als validatie. In Figuur B2.1 is te zien dat er een hoog voorjaarsbestand aanwezig was in het voorjaar van 2017 en een hoog winterbestand in de winter van 2018/2019.

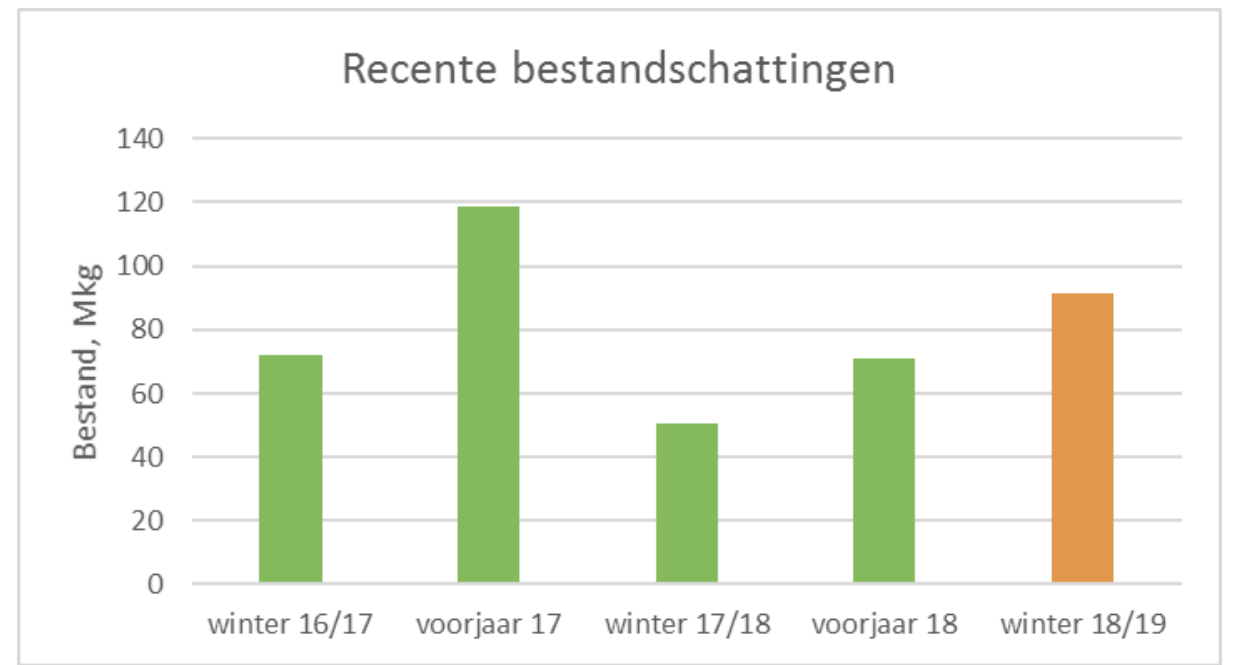

Figuur B2.1 Bestandschattingen vanaf de winter van 2016/2017

Het kan verwacht worden dat de (delen van) percelen die minder intensief gebruikt worden en die daarmee onder het grove grid vallen, vooral in gebruik zijn als er veel mosselen voor handen zijn. Dat dit inderdaad zo lijkt te zijn, is te zien in Figuur B2.2.

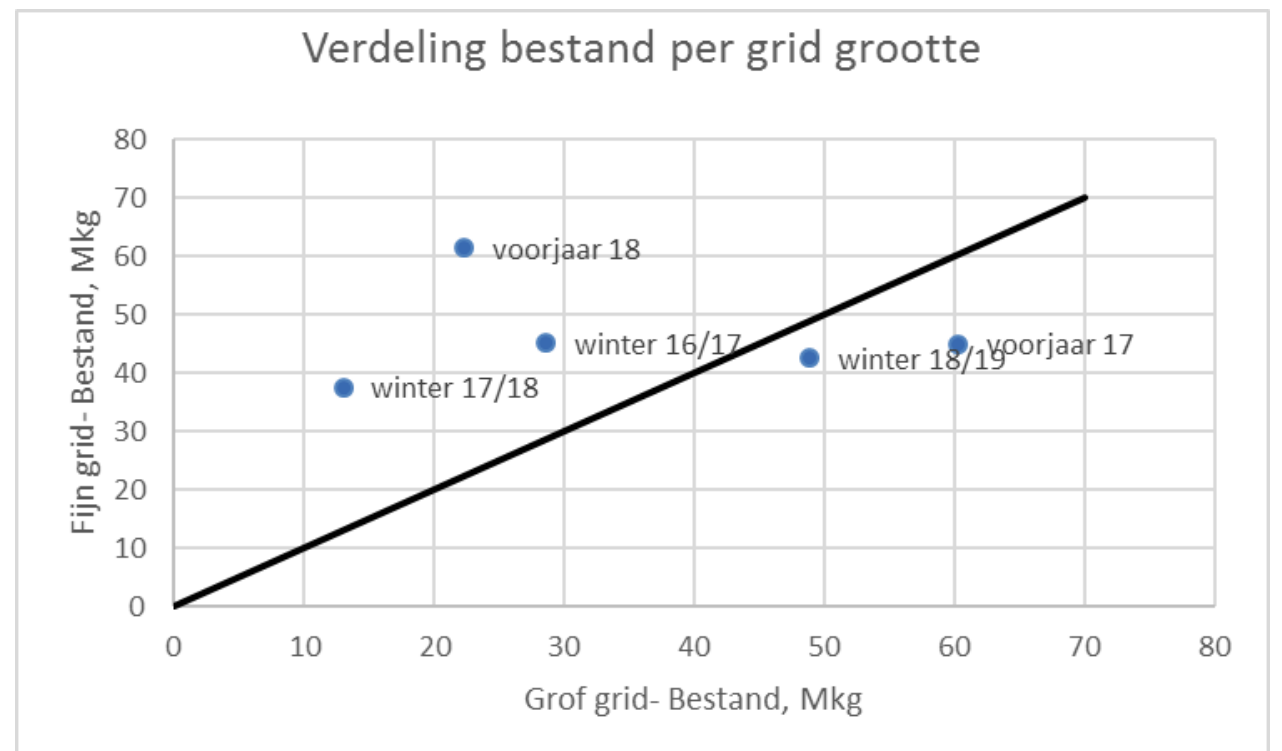

Figuur B2.2 Het mosselbestand op de arealen die met een fijn grid bemonsterd zijn ten opzichte van het mosselbestand op de arealen die met een grof grid bemonsterd zijn. 
In deze figuur is het bestand op de delen van het perceelareaal wat geclassificeerd is als intensief gebruikt (fijn grid) uitgedrukt ten opzichte van de delen van het perceelareaal die als minder intensief geclassificeerd zijn (fijn grid). Voor de opnames waar een relatief hoog mosselbestand aangetroffen is (voorjaar '17 en winter '18/'19, Figuur B2.1), was het mosselbestand hoger op de delen met het grove grid. Voor de andere opnames geldt dat het mosselbestand juist hoger was op de delen met het fijne grid.

Het areaal wat geclassificeerd is als minder intensief gebruikt is hierbij groter dan het areaal wat geclassificeerd is als intensief gebruikt: 2751 ha ten opzichte van 1776 ha. Dat leidt ertoe dat de mosseldichtheid lager is op het areaal met het grove grid, ook in de jaren waarin een relatief hoog bestand aanwezig was (Figuur B2.3). Figuur B2.3 laat ook zien dat de dichtheid van mosselen in de delen met het grove grid in jaren met een hoog bestand (voorjaar 2017 en winter 2018) hoger is dan in jaren met een laag bestand. Dit komt vooral door een intensiever gebruik, waardoor er minder stations zijn zonder mosselen of met mosselen in lage dichtheden.

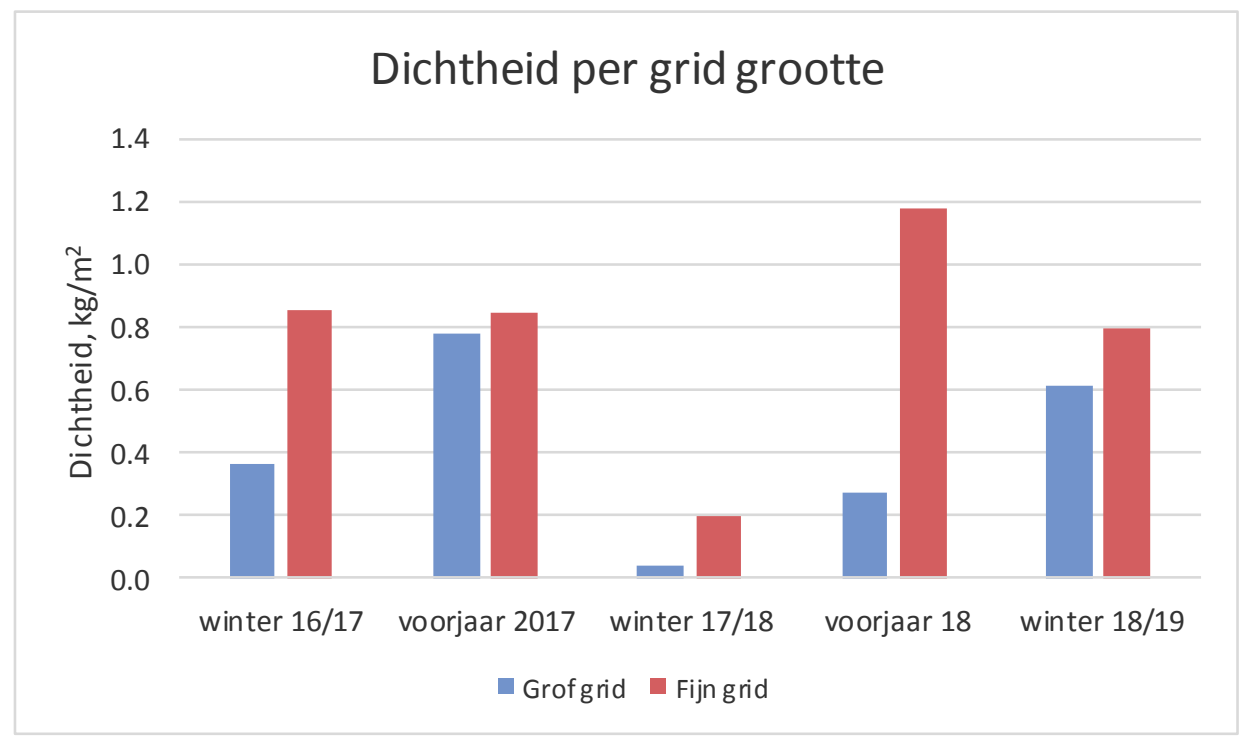

Figuur B2.3 Dichtheid mosselen $\left(\mathrm{kg} / \mathrm{m}^{2}\right)$ voor de bestandsopnames sinds de winter van '16/'17, waarbij een opdeling gemaakt is voor de gebieden met grof grid (minder intensief gebruikt) en met fijn grid (intensief gebruikt).

In Figuur B2.4 is geëvalueerd in hoeverre het opdelen van het monstergrid in een fijn en grof grid leidt tot verschil in bestandschatting. In het algemeen laat deze figuur zien dat de afwijking relatief klein is. De winteropname lijkt hierbij meer overeenkomst tussen beide methodes te laten zien dan de opname in het voorjaar. In de winter is de variatie waarschijnlijk kleiner, dan worden stormgevoelige percelen zo weinig mogelijk gebruikt. De schatting met het aangepaste monstergrid komt vrijwel overeen met de originele bestandschatting in de winter van '16/'17. 


\section{Bestandschattingen}

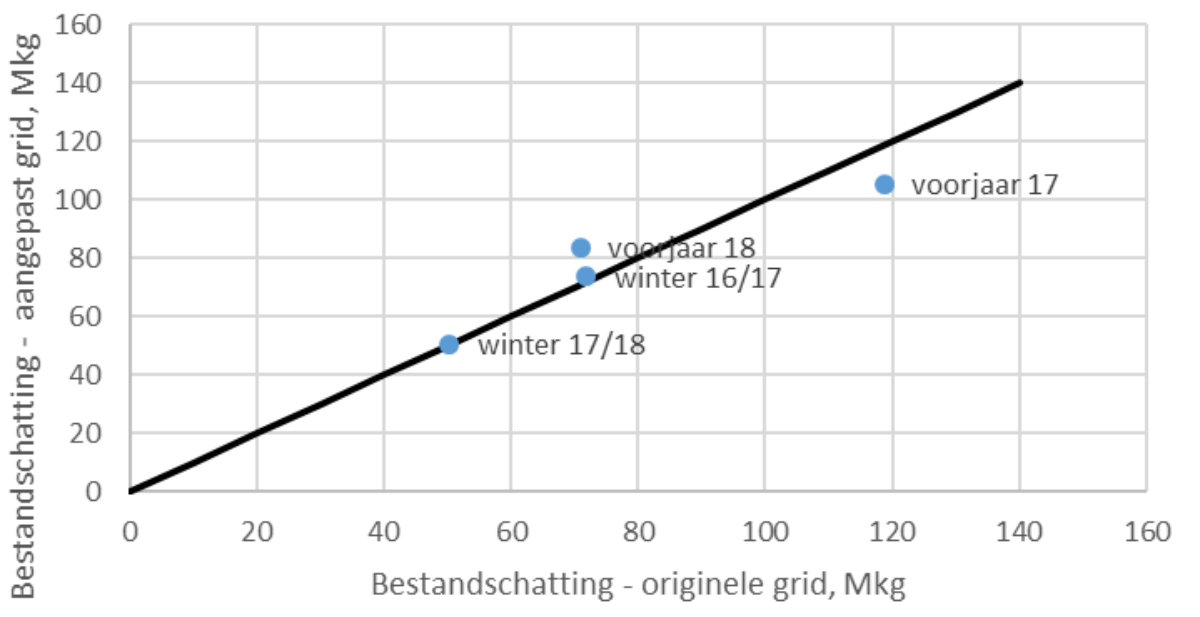

Figuur B2.4 Het mosselbestand op de arealen die met het originele (fijne) grid (Stratum 2) bemonsterd zijn, ten opzichte van het mosselbestand op de arealen die met het aangepaste (grove + fijne) grid (Stratum 1) bemonsterd zijn. 


\section{Bijlage 3 Protocol monstername}

\section{Handleiding bemonstering mosselpercelen}

versie 7 november 2014

\section{Monstername per station}

- Op elk station $\mathbf{5}$ happen

- Bij elkaar in een mand, spoelen

- Zeesterren uit de vangst halen, aantal noteren en bewaren in verzamel-emmer

- Idem voor krabben met schild groter dan $2 \mathrm{~cm}$ (duimnagel)

- Volume van de vangst bepalen in bekerglas. Aflezen in tienden liters. Wanneer het maar een paar mosselen zijn ("bewijsje") een "B" invullen. Wanneer er geen mosselen in de vangst zitten kan tarra over boord en is de vangst "nul".

- Bewaren in verzamelmand Zaad c.q. Halfwas + Cons. Bij mengsel indelen op dominante soort

- Aan dek: sample nummers ("treknummers" van die dag) invullen

- Brug: trek nummers noteren op de kaartjes.

\section{Invullen meetlijst aan dek}

De blauwe waarden moeten worden ingevuld, hier als voorbeeld

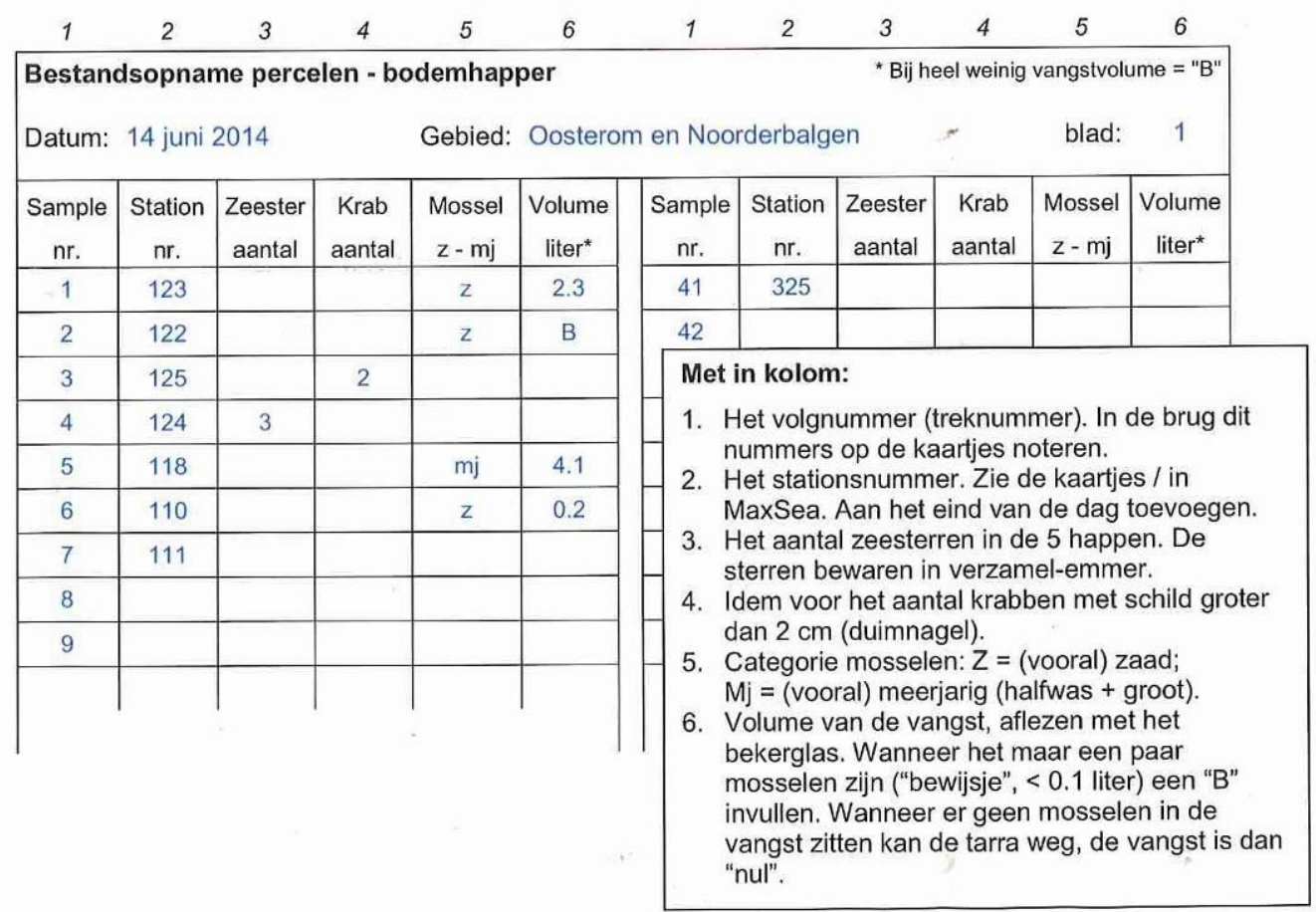




\section{Verwerken vangst per dag}

Uit de verzamelmanden wordt per dag een monster genomen en uitgezocht:

\section{Bepalen vangstvolume en het nemen van een subsample}

Van beide verzamelmanden vangstvolume bepalen in liters: grote zwarte emmer $=20$ liter, kleine zwarte emmer $=12$ liter of met maatbeker.

Volumes emmers graag nog even checken: Door de emmers met bekerglas te vullen met water.

- Vangst mengen en neem subsample op volume:

$>$ Zaad 3.5 liter $=1$ doorzichtig emmertje, uit "zaad" verzamel-mand

$>$ Meerjarig 6 liter $=$ wit emmertje, uit de andere mand

- Wanneer de vangst kleiner is dan 3.5 resp. 6 liter, dan de hele vangst als monster nemen.

\section{Uitzoeken subsamples}

Zie ook het voorbeeld zoals ingevulde tabel op volgende pagina

- Beide monsters liefst helemaal uitzoeken

- Uitzoeken op zaad, halfwas (= meerjarig en $<45 \mathrm{~mm}$ ) en groot (= meerj. en $>45 \mathrm{~mm}$ )

- Ontpokken

- Mosselen tellen en wegen, de kapotte mosselen alleen tellen

- Pokken wegen

- Zeesterren en krabben: tellen en wegen

- Bij later wegen de mosselen, krabben en zeesterren bewaren in water in verband met vochtverlies. 


\section{Bijlage 4 Kaarten mosseldichtheid per grootteklasse.}

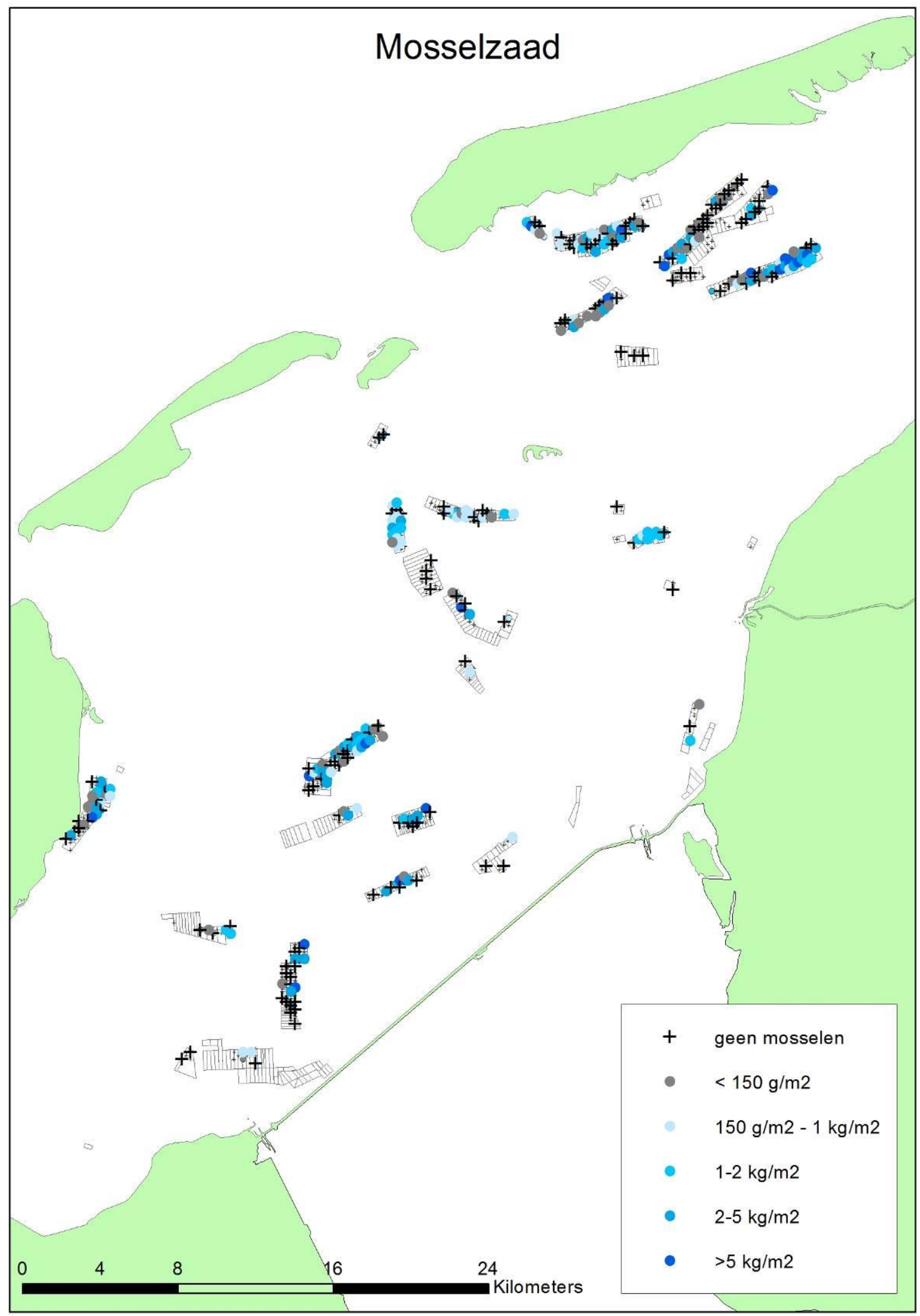




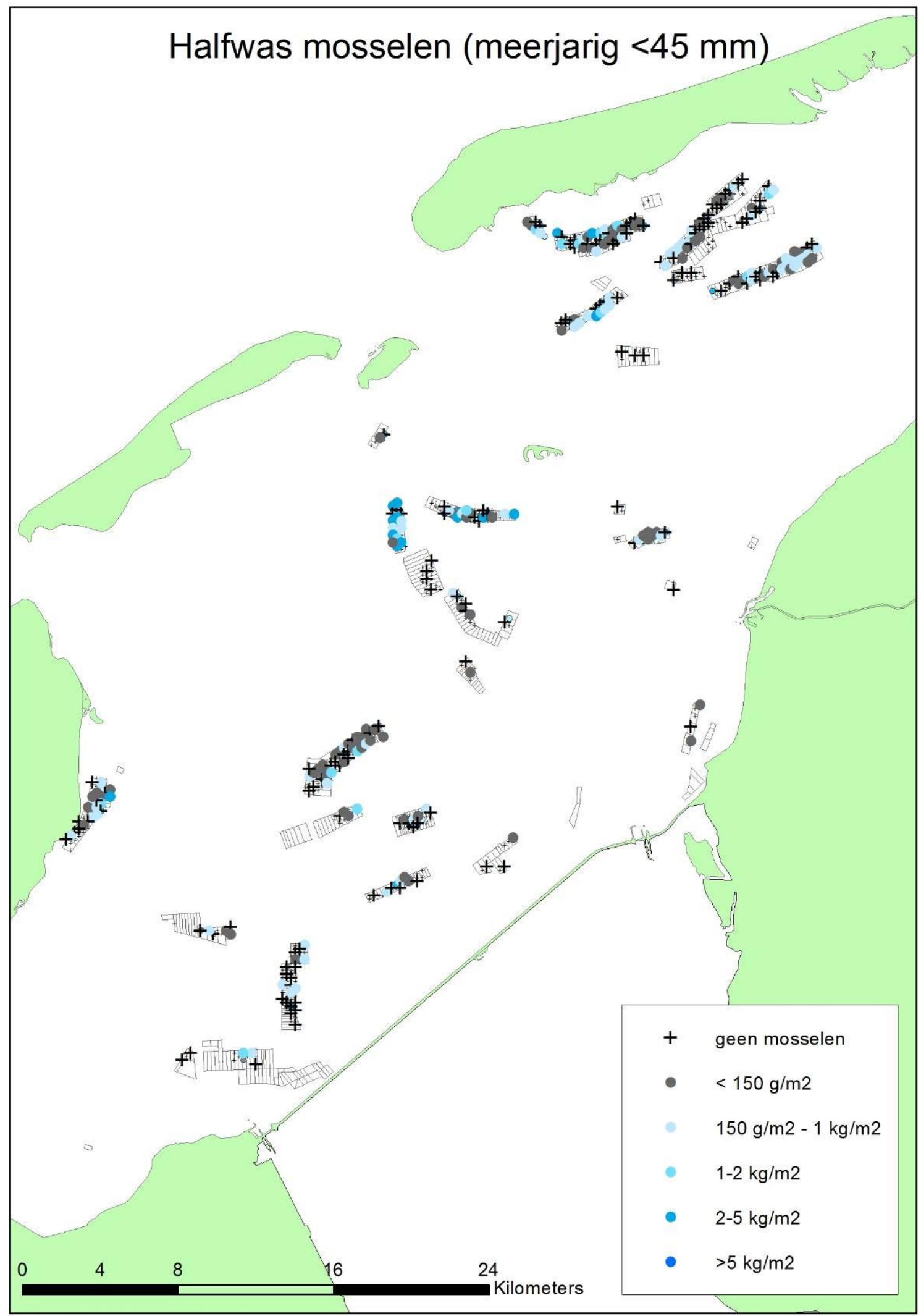




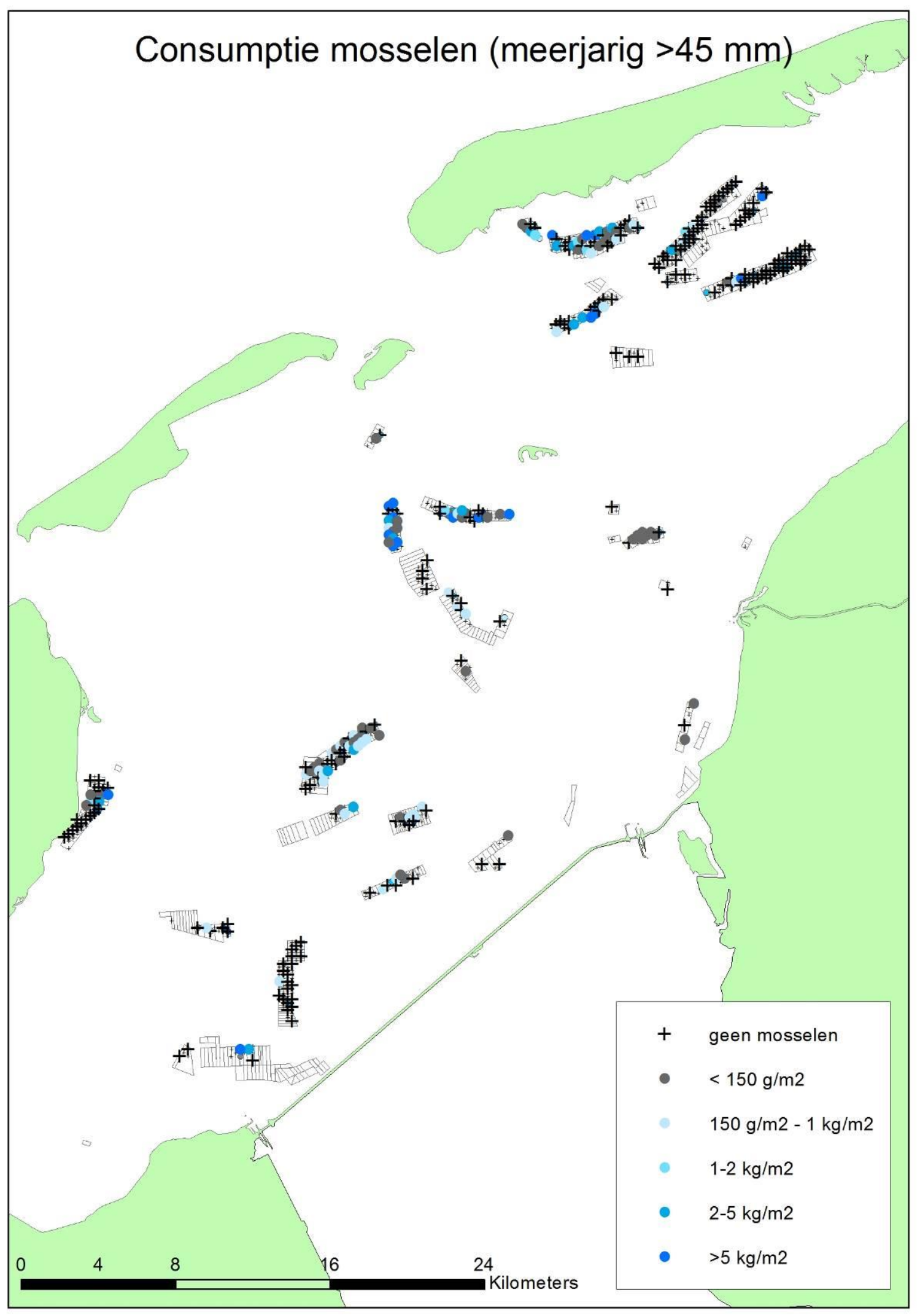


Wageningen Marine Research

T: +31 (0)317480900

E: marine-research@wur.nl

www.wur.nl/marine-research

Bezoekers adres:

- Ankerpark 271781 AG Den Helder

- Korringaweg 7, 4401 NT Yerseke

- Haringkade 1, 1976 CP IJmuiden
Wageningen Marine Research levert met kennis, onafhankelijk wetenschappelijk onderzoek en advies een wezenlijke bijdrage aan een duurzamer, zorgvuldiger beheer, gebruik en bescherming van de natuurlijke rijkdommen in zee-, kust- en zoetwatergebieden.

Wageningen Marine Research is onderdeel van Wageningen University \& Research. Wageningen University \& Research is het samenwerkingsverband tussen Wageningen University en Stichting Wageningen Research en heeft als missie: 'To explore the potential of nature to improve the quality of life' 